\title{
Construction of xAPI-based Multimedia Interaction Technology in Architectural Design Teaching
}

\author{
https://doi.org/10.3991/ijet.v12i07.7220 \\ Haiou Wang \\ University of Science and Technology Liaoning, Anshan, China \\ anshanwyq@163.com
}

\begin{abstract}
Architectural design involves both aesthetic design and mechanical calculation. It is not limited to theoretical graphics, but also needs practical support. Traditional multimedia teaching only provides static display of design drawing and passive teaching. In this mode, students cannot understand design philosophy well, students' creativity and imagination are restricted, and the problem of learning differentiation due to difference of individual students cannot be solved. Hence, a teaching software that makes use of FLASH for display and is based on XAPI multimedia interaction technology is put forward for architectural design in this paper. Remarkable achievements of its application in teaching have been made, which is helpful to arouse students' interest in courses, deepen students' understanding of design, and relieve students' learning score differentiation due to individual difference of students' learning ability.
\end{abstract}

Keywords-Multimedia interaction technology, xAPI, architectural design, teaching

\section{Introduction}

Multimedia interaction technology refers to a technique of realizing man-computer conversation via input and output of computer [1]. Specifically, it involves pictures, audios, texts, videos, and such information displayed to human via computer display, voice box, and such output devices, and instructions and answers input by human via microphone, keyboard, and such input devices. The application of multimedia interaction technology in teaching experiment is helpful to make teaching more interesting, and arouse students' enthusiasm. Multimedia comes with abundant display forms and massive content, which greatly helps students acquire visual knowledge rapidly. Presently, the application of multimedia in architectural design teaching is limited to display of pictures and slides and computer-aided calculation. In other words, multimedia is utilized to realize dynamic presentation and unidirectional teaching only, and interaction with students has not been realized yet [7]. Hence, it is in bad need for a multimedia teaching technique to take the place of teachers to interact with students and record students' feedback in real time. Meanwhile, multimedia is liable to make teaching course lengthy and boring, which exerts a poor effect in arousing students' enthusiasm, and in education and teaching. With the wide application of multimedia 
technique and the popularization of electronic equipment, more and more students are attracted and show favor to electronic equipment-aided learning. In view of this, to adapt to new teaching needs, it is necessary to develop a teaching system that is for displaying teaching content with the help of multimedia interaction technology and can be widely used via various electronic equipment.

\section{Research Progress Review}

Multimedia interaction technology has been applied in teaching practice of several subjects, among which the typical subjects include animation design and language study. Imran et al. believed although these platforms are a good way to link with offcampus students, they often cannot realize two-way communication between a student and a teacher, and the interactivity with the content. The effect of online courses is weakened due to the lack of real-time interactivity and right communication channel. To solve this problem, we propose to use an intelligent pedagogical media that is called hyper interactive presenter (HIP) [2]. Maaruf and Siraj will use interactive multimedia to enhance culturally responsive pedagogical module as teaching tools and materials. Using developmental research design, samples of sixty secondary school students of cross ethnicity and two arts education teachers are taken for the study. Findings of this study indicate that it is helpful to create cultural awareness and increase the knowledge regarding cultural diversity by 're-purposing' the technology and by including teachers as co-designers in the development of modules and teaching materials. Subsequently, the findings demonstrate also that teachers become more culturally tolerant and students participate more in the learning process [3]. Leow and Neo constructed an interactive teaching-learning module at INTI International College, which is constituted by Gagne's teaching mode, multimedia, and studentcentered learning. The results show that the multimedia interactivity is effective in significantly improving students' performance. Students also have positively changed their attitudes [4]. Researchers constructed a VOD service platform based on broadband multimedia technique according to the problems that the traditional way of receiving video and audio is subject to time constraints and users are passive. This platform is intended to render on-campus interactive multimedia video on demand service, to ultimately realize real-time video on demand service and continuity of data transmission. It has undergone half-year trial run, and has been being in good condition, which demonstrates the practicability of the system [5]. Sun et al. combined Storyline software with network interactive courseware, and applied the combination in the course of Medical Microbiology. Their practice demonstrates the application advantages of the courseware, and that teaching aids play an important role in promoting students' interest in independent study [6].

Architectural design involves both aesthetic design and mechanical calculation. It is not limited to theoretical graphics, but also needs practical support. In traditional teaching practice, effect pictures and structure charts cannot be displayed visually, and printed books are provided with little power of expression, which both have an adverse effect in enhancing students' understanding of design. Besides, it is unafford- 
able in both economy and time for most students to make field research of the design of famous buildings around the world. In view of this situation, it is urgent to develop a multimedia technique for three-dimensional and all-around display to help student's understanding.

According to the design of this paper, a teaching system based on Experience API (xAPI) multimedia interactive technique will be constructed first, and then vivid presentation of knowledge will be realized with FLASH, to enrich the channels of knowledge acquisition for students. This system is compatible with smart phone, IPAD and such mobile terminals. With this system, it is expected to realize all-around presentation of architectures with the help of multimedia interaction technology, interaction between students and computer, real-time recording of students' learning state, and recommending courses and customizing a review plan according to students' actual situation. It is helpful for students to rapidly acquire desired courses in class, and complete assignments within their competency after class.

\section{Model Analysis}

The popularization of computer technology, network and multimedia has enriched students' channel for knowledge acquisition, and drastically changed the traditional mode of presentation to group in fixed location. But there are still defects. Firstly, there is lacks a uniform platform and a channel for integrating learning resources. As learning software mushroom, students can learn professional terms of architecture, architecture structure drawing and perspective drawing, and so on with the help of different software. As a result, they acquire fragmented knowledge points, and have to integrate the knowledge points by themselves. Secondly, non-traditional learning style is not as controllable as traditional learning style. In learning process, traditional teacher-centered teaching only accounts for $10 \%$ of students' learning life, and students mainly acquire knowledge from upperclassmen' learning experience, teachers by after-class tutoring, online videos, lecturers and trainings. These contents cannot be recorded systematically.

Experience API (xAPI) standard doesn't only provide traditional fixed teaching and examination and evaluation means, but also enable recording and analyzing other unconventional learning activities [9]. The core of the standard is the "Statement" and "Learning Report Store (LRS) [10]. The Statement is to describe learning activity in the form of "Actor + Verb + Object". All learning activities are described and stored in such a simple structure. Statement involves ten attributes, including three required options of Actor, Verb, Object, and Result, Context, Timestamp, Stored, Authority, Version optional attributes [11].

According to Table 1, the Statement is presented mainly in the form of "What I am doing (Noun, Verb, Object)" or "I did this". Not all activities can be included in the Statement. Instead, learning events should be defined with learner as the center, based on learning action, and in combination with smart learning method. For example, a student watched a teaching video, clicked a button, slid a picture, chose an option, and so on. 
LRS can be of a distributed storage environment similar to database that is for storing the learning data of students at any learning platform. The data flow diagram of LRS is as shown in Figure 1. LRS can come independently or be embedded in Learning Management System (LMS). If it is the latter case, LMS sends the Statement to LRS for storage, and the learning report generated in LRS can be transmitted to LMS, independent LRS and Reporting Tools. The data in LRS can be interchanged and synchronized among different LRS, which ensures the integrity and mobility of data.

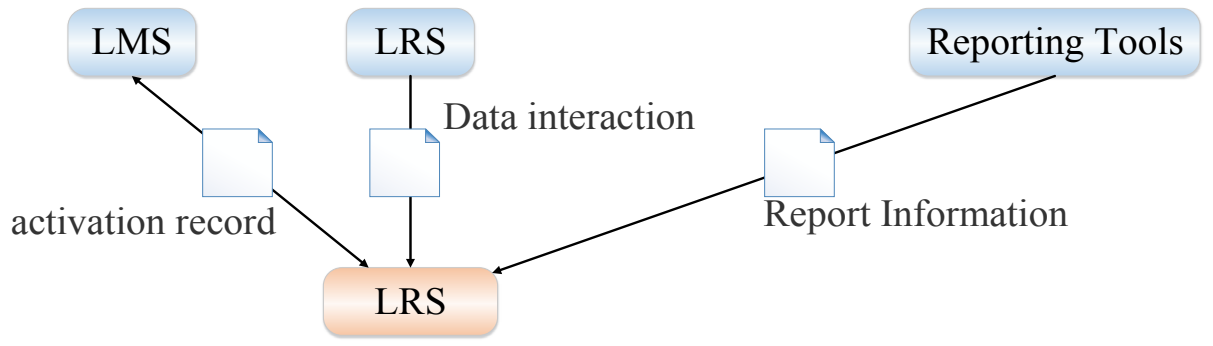

Fig. 1. LRS data flow diagram

On the whole, it is not exaggerated to call xAPI the main artery of the learning system. Learning data circulates in it like blood, and provides nutrients to learning software, and the Statement on learners pours nutrients into the blood. It accepts data from various types of learning software, and feeds back to learners and teachers, ensuring healthy and stable learning activities.

Normalized recording of learning activities makes the data stored in LRS be featured by structuralization and semi-structuralization, which, together with LRS, is completely in conformity with the characteristics of big data. Hence, the interaction technology that is based on xAPI with the characteristics of big data in this paper cannot only realize teaching content setting, interactivity between students and learning system, and customized learning method, but also recommend learning materials and enrich learning resources based on big data analysis and recommendation.

\section{Construction of Xapi-Based Multimedia Interaction System}

The system is designed to present contents by means of FLASH, which subverts static presentation of traditional printed data and PPT, and arouses students' interest. Besides, it also realizes man-machine interaction in course design based on xAPI standard, and then realizes teaching students in accordance of their aptitude.

\subsection{System analysis}

For building this system, three problems should be solved first, namely selection of learning resources, design of learning engine, and implementation of learning activities. 
Selection of learning resources : Both traditional teaching method and new multimedia-aided teaching method cannot do without teaching resources, namely teacher's instruction. Teaching resources can be presented via video and audio of teacher's instruction, textbook, picture, journal article, or webpage.

Design of learning engine : The learning engine should consist of four modules, namely learner, knowledge base, prediction and recommendation. The design of learning engine requires learner and knowledge first to record learner's basic information, learning habit, and cognitive level and update the information from time to time. To realize individualized learning, the knowledge structure and related concepts of specific field are required. Prediction means predicating the content and form of further learning based on students' current knowledge level and receptivity. Recommendation refers to recommending learning content to learners based on the results of prediction and the reserve of knowledge base.

Implementation of learning activities: The system will be presented mainly by means of FLASH via smart phone, IPAD, PC, etc., with which learning can be realized at any time anywhere. Both customized and self-adaptive learning modes are available. Customization means that students can subscribe learning contents, study plan and evaluation contents according to their own situation. Self-adaption means the system automatically make a study plan and design learning contents for a student according to his/her knowledge base and learning ability, which can be referred to by students for customization.

\subsection{Design of system architecture}

According to the system analysis in Fig. 3, the system frame diagram is as below in Figure 2. Learning data bank is a storage bank of "learning materials". Teaching software is mainly for "implementation of learning activities". It can directly read the desired learning materials from the learning data bank for customizing learning contents, and acquire contents for self-adaptive study plan from the recommended contents by the learning engine. Students' every learning activity on the software will be recorded in LRS. The learning engine analyzes student behaviors according to the Statement of students in LRS, and recommends learning contents based on the contents in the learning data bank and give a feedback to teaching software.

Teaching software is the core for fulfilling teaching activities. The teaching software of the system mainly has the following functions, including learning resource allocation, teaching activity, and study plan making. Learning resource allocation covers appreciation and analysis of Chinese and foreign classic architectures, perspective drawing, basic concepts of architecture, and professional English. Teaching activities consists of learning, review and appraisal. Study plan making consists of selfadaptive study plan, customized study plan and study plan adjustment. Please see Figure 3 for the application framework of teaching software. 


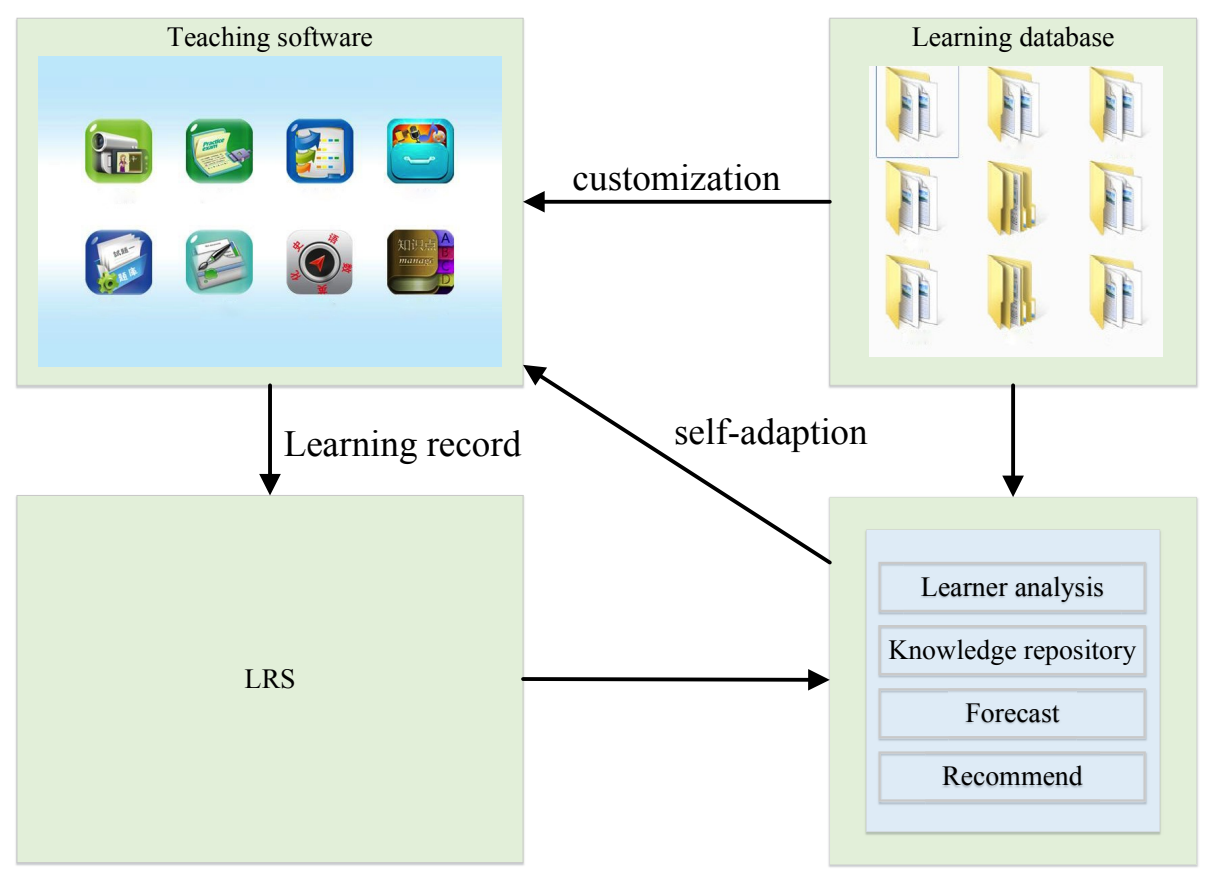

Fig. 2. Structure diagram of video module

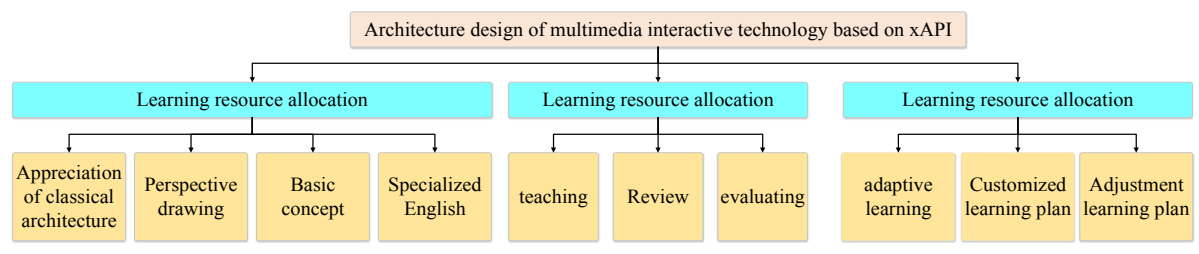

Fig. 3. Application framework of teaching software

\subsection{System function display}

The functions of the architectural design teaching software based on xAPI multimedia interaction technology are as shown in Figure 4.

1. System permissions are preset for system administrator, teacher and student respectively. System administrator mainly maintains basic information of system, such as basic student information input, basic teacher information input, etc. Teacher can view his/her students' learning condition and test scores. Student can view his/her own study plan, course information and test content only.

2. User should input his/her user name and password to log in. The default user name and password both are student number. 


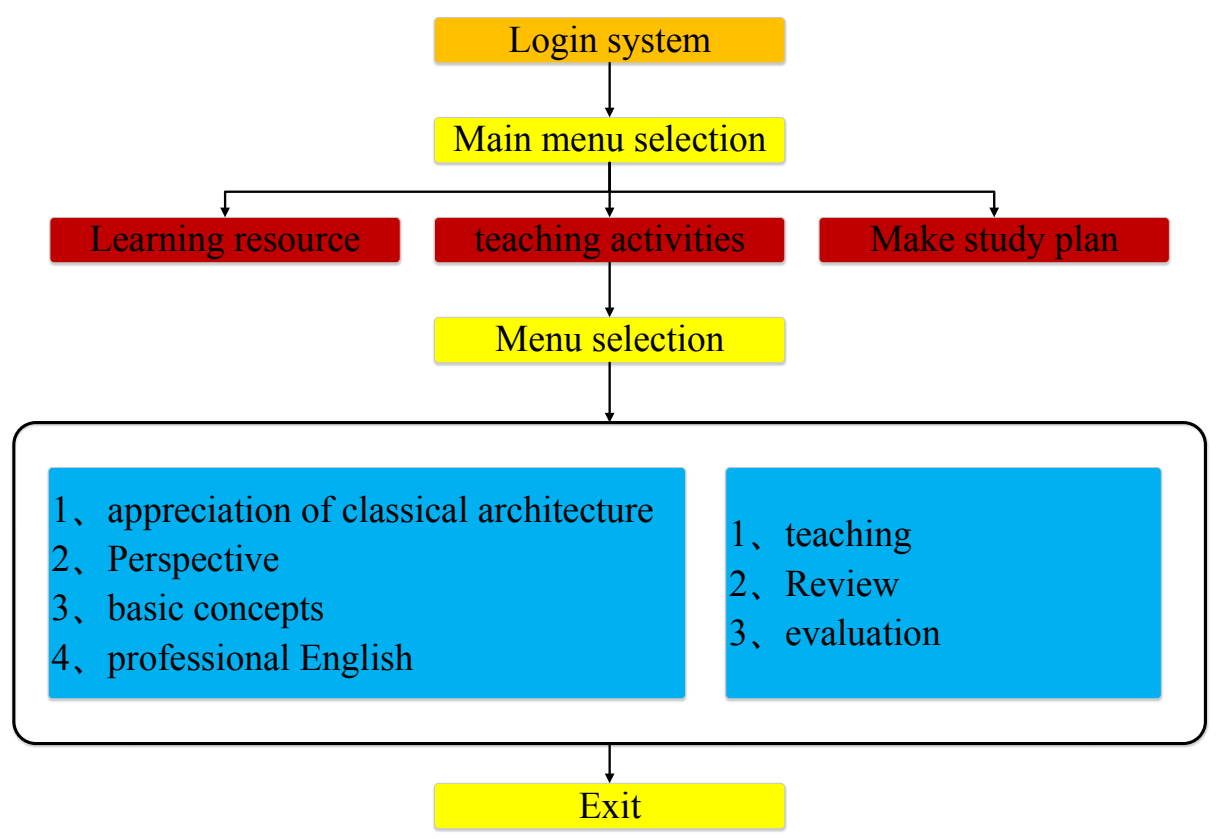

Fig. 4. Structure diagram of audio module

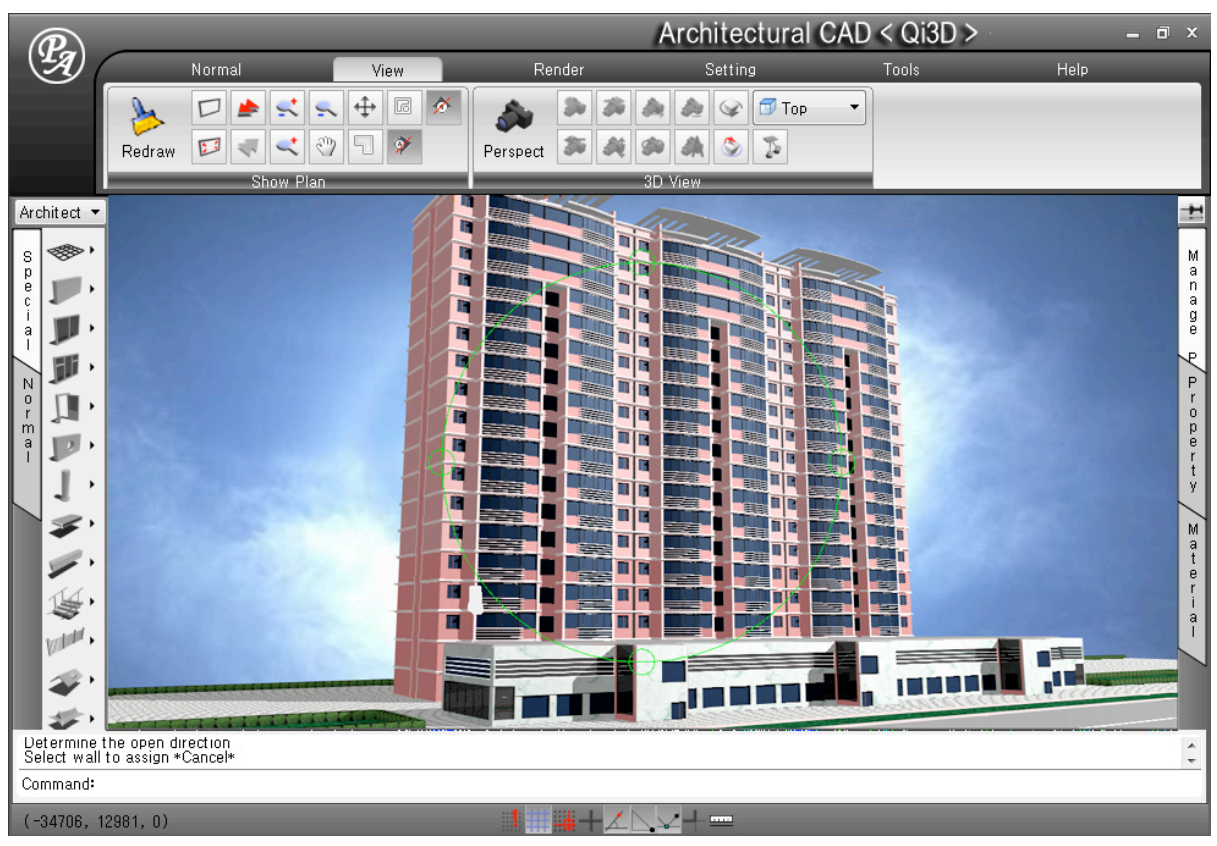

Fig. 5. Software production process display 


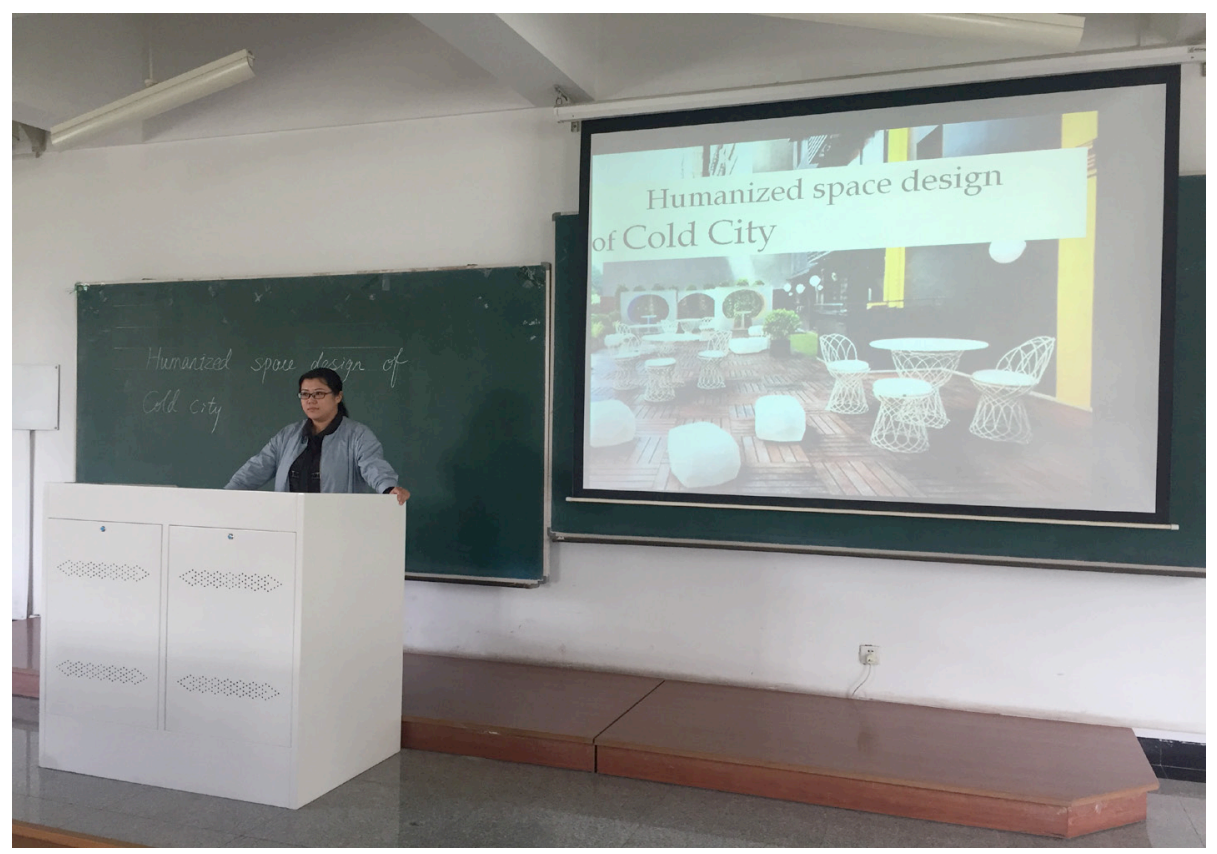

Fig. 6. Learning resource configuration page display

3. After entering the system, user can see the main menu of function consisting of learning resource allocation (for learning resource input), teaching activities (for students' learning) and study plan making (for individualized study plan making).

4. If you click learning resource allocation, a submenu will drop down, which consists of appreciation and analysis of Chinese and foreign classic architectures, perspective drawing, basic concepts and professional English. You can click the desired item for watching and learning and upload new resources. The four items all are learning contents. Both teacher and student can add other types of learning content by adding classifications.

5. If you click teaching activities, a submenu consisting of teaching, review and appraisal will drop down. Teaching is for watching teaching video or courseware to learn specific contents; review is for reviewing the learned courses; appraisal is to be performed in two modes, namely self-appraisal and examination. Self-appraisal is for reviewing and checking the learned contents, and examination is for evaluating students' academic performance.

6. If you click study plan making, a submenu consisting of customized study plan, self-adaptive study plan and study plan adjustment will drop down. Customized study plan relates to teaching plan designated by teacher according to student's learning condition. Self-adaptive study plan refers to learning contents and study plan automatically generated by the system according to student's learning condition and learning assessment. Study plan adjustment enables user to view the automatically generated study plan and the one designated by teacher in this page, and student can adjust his/her study plan on this basis according to his/her own sit- 
uation. Study plan mainly covers content of review, appraisal period, and learning content.

7. Logout enables user to $\log$ out the system in a safe way, to avoid information disclosure and ensure information safety and individual privacy.

\subsection{Effect analysis}

In this paper, a contrast experiment was designed to research the effect of xAPIbased multimedia interaction technology in architectural design teaching. For this purpose, six classes of architecture specialty of Grade 2012 of University of Science and Technology Liaoning in Liaoning province were sampled at random to comparing how they accept the course of humanization design of public space in cold-weather cities in architectural design teaching. Three classes were taken as the experimental group, and the other three classes as the control group. The comparison was made from four aspects, including understanding level of design content, academic record of architectural design course, improvement in midsemester and at the end of semester, and variance of final grade.

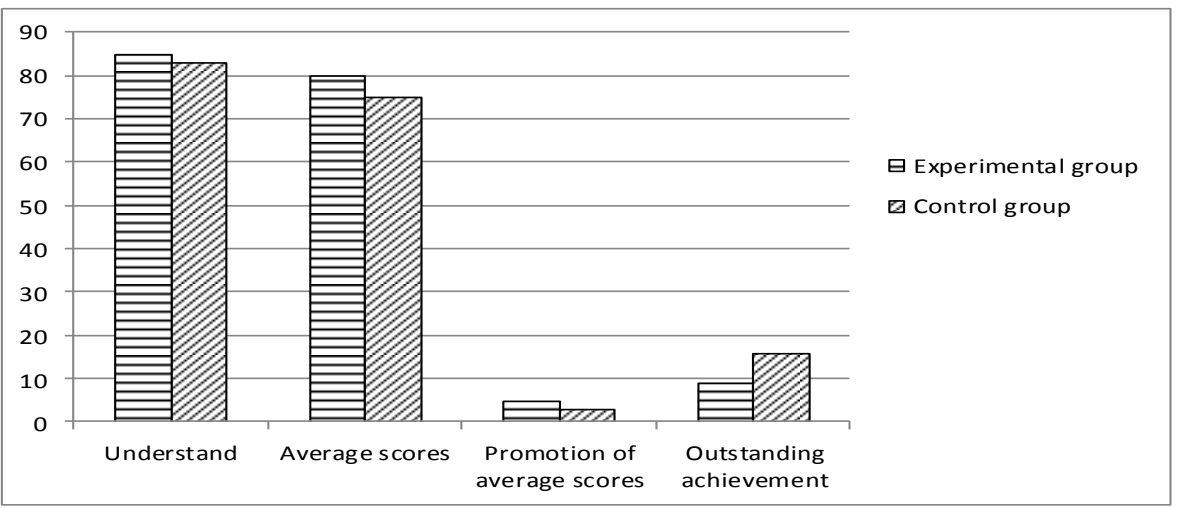

Fig. 7. Contrast diagram of teaching effect between experimental group and control group

According to the figure above, since dynamic demonstration with the help of FLASH was adopted, the pictures and design philosophy can be presented dynamically, and the experimental group performed better than the control group in understanding the course. But the effect is instantaneous and not lasting.

Since the application of xAPI-based multimedia interaction technology makes teaching more interesting, enables visual presentation of architectural design, helps students understand the course, enriches learning content, and provides proper review and self-appraisal modules, it is helpful to improve students' academic performance. Accordingly, the average score of final exam of the experimental group is significantly higher than that of the control group; the experimental group performs significantly better than the control group in improvement of average score, indicating the system is effective if it is adopted for a long time; the final grade indicates that students de- 
vote efforts to study at different degrees due to individualized difference. One of the features of the system is that individualized study plans and learning contents can be designed according to the actual situation of students to help every student understand the courses.

\section{Conclusions}

In this paper, a system framework is designed for applying XAPI-based multimedia interaction technology in architectural design teaching, and it is applied in practical teaching. The system designed in this paper is helpful to improve students' understanding of design and xAPI technology, is student-oriented, provides interactive learning resources supported by xAPI standard data, and can greatly stimulate students' learning interest, arouse students' enthusiasm for study, guide students' learning process, and help students to perform self-assessment.

\section{Acknowledgment}

This work was supported in part by the Soft Research Project of the Ministry of Housing and Urban-Rural Development (MoHURD) (No. 2013-K3-2).

\section{$7 \quad$ References}

[1] Ali, A.M., Richardson, J. Using web interactive multimedia technology: Several approaches, International Journal of Technologies in Learning, 2015, vol. 22, pp. 43-54. https://doi.org/10.18848/2327-0144/CGP/v22i02/49164

[2] Zande R V. Creating the Urban Village: Teaching Pre-Service Teachers about Sustainable Design in Architecture and Community Planning[J]. International Journal of Art \& Design Education, 2010, 29(3):321-329. https://doi.org/10.1111/j.1476-8070.2010.01659.x

[3] Imran, A.S., Kowalski, S.J. HIP - A Technology-Rich and Interactive Multimedia Pedagogical Platform, Lecture Notes in Computer Science, 2014, vol. 8523, pp. 151-160. https://doi.org/10.1007/978-3-319-07482-5 15

[4] Maaruf, S.Z., Siraj, S. The State of Technology and the Arts - Interactive Multimedia in Enhancing Culturally Responsive Pedagogy, Procedia - Social and Behavioral Sciences, 2013, vol. 103, pp. 1171-1180. https://doi.org/10.1016/j.sbspro.2013.10.444

[5] Leow, F.T., Neo, M. Interactive Multimedia Learning: Innovating Classroom Education in a Malaysian University, Turkish Online Journal of Educational Technology, 2014, vol. 13(2), pp. 99-110.

[6] Zhang, S., Liu, Y.Y. Research on Video on demand based on broadband multimedia technology, Techniques of Automation and Applications, 2016, vol. 35(11), pp. 145-146.

[7] Sun, L.H., Guo, M.Y. Using Storyline to develop network-based interactive courseware of medical microbiology, China Medical Education Technology, 2014, vol. 134A(3), pp. 346-346.

[8] Kevan, J.M., Ryan P R. Experience API: Flexible, Decentralized and Activity-Centric Data Collection, Technology, Knowledge and Learning, 2016, vol. 21(1), pp. 143-149. https://doi.org/10.1007/s10758-015-9260-x 
[9] Horridge, M., Bechhofer, S. The OWL API: A Java API for OWL ontologies, Semantic Web, 2011, vol. 2(1), pp. 11-21.

[10] Bergeron, B. Application of learning record stores and other forms of electronic competency records in modeling competency degradation, Stud Health Technol Inform, 2014, vol. 196, pp. 23-28.

[11] Mclaren, W., Pritchard, B., Rios, D., et al. Deriving the consequences of genomic variants with the Ensembl API and SNP Effect Predictor, Bioinformatics, 2010, vol. 26(16), pp. 2069-2070. https://doi.org/10.1093/bioinformatics/btq330

\section{Author}

Haiou Wang is an associate professor in the School of Architecture and Fine Art Design, University of Science and Technology Liaoning, Anshan 114051, China, (anshanwyq@163.com).

Article submitted 11 March 2017. Published as resubmitted by the authors 27 May 2017. 